\title{
Model Equation Based on the 8 Groups and the 7 Periods in the Periodic Table of Elements
}

\author{
Orwa Houshia (Corresponding author) \\ Department of Applied Chemistry, Arab American University \\ P.O. Box 240, Jenin, WestBank, Palestine \\ Tel: +972-59-282-5885Ｅ-mail: orwa.houshia@aaup.edu \\ Harbi Daraghmeh \\ Department of Applied Chemistry, Arab American University \\ P.O. Box 240, Jenin, WestBank, Palestine \\ Naba Abuhafez \\ Institut des Sciences Chimiques de Rennes - UMR CNRS 6226 \\ Université de Rennes 1 \\ Campus de Beaulieu - Bât. 10B \\ F-35042 Rennes Cedex, France
}

Ahmad Abdelraouf Jrar

MedPlusLab, Jenin, WestBank, Palestine

Received: June 9, $2021 \quad$ Accepted: July 25, $2021 \quad$ Published: August 11, 2021

doi: 10.5296/ire.v9i2.18723 URL: https://doi.org/10.5296/ire.v9i2.18723

\begin{abstract}
The periodic table of chemistry contains all synthetic and naturally occurring elements. The elements are arranged in seven horizontal periods from left to right with increasing atomic number. The periodic table is divided into two groups: metals and nonmetals, within elements
\end{abstract}


moving from left to right, the elements get less metallic, culminating in nonmetals on the far right side of the table. Further, the elements are also arranged in eight vertical columns or groups for those with similar physical and chemical properties. A model equation has been developed based on the 8-group and the 7-periods from which trends of elements has been calculated. Among the trends in the periodic table that were calculated are ionization energy, atomic size and effective nuclear charge. It has been discovered that the calculated theoretical values from the model equation rhyme well with the actual values for each element with few exceptions.

Keywords: Periodic table, Groups, Periods, Ionization energy, Atomic size, Nuclear charge

\section{Introduction}

The periodic table is the most important chemical reference for elements in existence. It organizes all known elements in an information matrix. The elements are arranged in the order of increasing ordinal number from left to right and from top to bottom. The order generally coincides with the increase in atomic mass. The periodic table is very important. The periodic table contains 119 elements in a very discrete order to show similarities and differences in chemical properties. There are 94 naturally occurring elements and the other 25 were made synthetically using particle accelerators. Elements are classified in the periodic table as metallic and non-metallic elements with a dark rung that corresponds to metalloids. metals are left and then none-metals. The rows are also organized so that items with similar properties are in the same columns. The table is a two-row block of elements that contain the lanthanides and actinides. These groups are classified as inner transition metals.

The position of the elements in the periodic table is very important due to the trends in chemical properties in groups and rows. An element's properties can essentially be projected based on its position in the periodic table. It's important to remember that trends work differently when moving vertically and horizontally across the table. Trends within groups are explained by the common arrangement of electrons in their valence shells, and thus have creates similarities in atomic radius, electronegativity and ionization energy. The atomic radii of the elements increase from top to bottom. Similarly, the ionization energy and electronegativity decrease due to the configuration of the electrons. The periods also show similar trends in terms of electronegativity and ionization energy, atomic radii and electron affinity. If you move from left to right within a period, the atomic radii fall and cause the ionization energy to increase. As you move from left to right, electronegativity and electron affinity also increase.

The periodic table was formerly known as the periodic table of the Russian chemist Dmitry Mendeleev (Dmitry Mendeleev), who first created the periodic table in 1869. However, the old periodic table is not as extensive as the modern periodic table. Since its first creation, new elements have been discovered and added to the original periodic table. Others, such as John Newlands in London, Alexander Beguerd Shancourtois in France and Julius Lothar Meyer in Germany, Made an important contribution to the first periodic table. In 1860, the publication of more precise atomic masses (such as relative atomic masses) helped everyone. First, only 60 elements were found (more than 100 are now known), and secondly, some information 
about these 60 elements were all incorrect. It was as if Mendeleev was doing a puzzle with one third of the fragments missing, and other pieces twisted!

Mendeleev had written the properties of the elements on pieces of cardboard and, according to tradition, after arranging the cards while patiently playing, suddenly realized that by arranging the element cards in the order of increasing atomic weight, certain types of objects were regularly presented to the Russian Physico-Chemical Society. They were read by Professor Menschutkin because Mendeleev was sick. His ideas were later published in the leading German chemical magazine of the time, the Zeitschrift für Chemie. What Mendeleev did not predict was the discovery of an entirely new group of elements, the noble gases, by the Scotsman William Ramsay and his collaborators in the last decade of the 19th century. Mendeleev was initially dismayed by this, but before he died in 1907, he realized that Ramsay's discoveries were further evidence for the periodic table, not a contradiction. Ramsay received a Nobel Prize for discovering five elements. Mendeleev never received this honor. The element, atomic number 101, is named after Mendeleev, an even rarer distinction. This is certainly deserved by the original formulator of the periodic table.

In this work a unitless equation used as a coding of some of the physical properties of elements is introduced, and can be used in high school textbooks to show various trends of elements in periodic table. The theoretical data obtained from using this equation goes hand in hand with actual data for each element the periodic table trend.

\section{Methodology}

The researchers used Computer Excel sheet to perform calculation by applying on the theoretical equation:

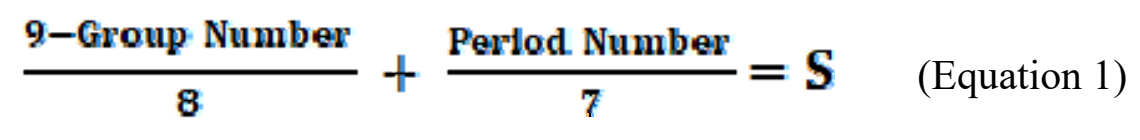

Where,

S: Special Number for each elements.

$8=$ eight groups of the periodic table

$7=$ seven periods of the periodic table

$9=$ factor

\subsection{Atomic Size}

To compare atomic sizes between the elements, we substitute the location for each element (i.e. group number and period number) in the Eq.1 and compare the result of the element with other. The element which has the biggest number is the largest in size, then the next one and so on. 


\subsection{Effective Nuclear Charge}

To compare between the elements in the effective nuclear charge, we substitute the location of the element in the periodic table (group and period) Eq.1 and compare the result of the element with other, the element which has the biggest number is the largest in effective nuclear charge, then the next one and so on.

\subsection{Ionization Energy}

To compare data between the elements in the ionization energy, compensate for each element in the Eq.1 and compare the result of the element with other, the element which has the lowest number is the largest ionization energy, then the next one with taking the consideration for the case of anomalies in the group 5 with 6 , and 2 with 3, (If the group number of the element is 5 turned into 6 also If the group number of the element is 2 turned into 3 , and the vice versa. After the conversion compensated in the equation and compare with other elements, but at the first; the first ionization energy compared).

\section{Results}

By using Excel program and the Eq.1 we obtain the following data show in Table 1. Using this data and the atomic size, the effective nuclear charge and the ionization energy definition elements arrange as shown in Tables 2, 3 and 4, sequentially, also there is a unique number for each elements.

Table 1. Theoretical data acquired by applying Equation (1) on the periodic table for each elements

\begin{tabular}{cccccc}
\hline Element & $\boldsymbol{S}$ & Element & $\boldsymbol{S}$ & Element & $\boldsymbol{S}$ \\
\hline Hydrogen & 1.142857 & Argon & 0.553571 & Cesium & 1.857143 \\
Helium & 0.267857 & Potassium & 1.571429 & Barium & 1.732143 \\
Lithium & 1.285714 & Calcium & 1.446429 & Thallium & 1.607143 \\
Beryllium & 1.160714 & Gallium & 1.321429 & Lead & 1.482143 \\
Boron & 1.035714 & Germanium & 1.196429 & Bismuth & 1.357143 \\
Carbon & 0.910714 & Arsenic & 1.071429 & Polonium & 1.232143 \\
Nitrogen & 0.785714 & Selenium & 0.946429 & Astatine & 1.107143 \\
Oxygen & 0.660714 & Bromine & 0.821429 & Radon & 0.982143 \\
Fluorine & 0.535714 & Krypton & 0.696429 & Francium & 2 \\
Neon & 0.410714 & Rubidium & 1.714286 & Radium & 1.875 \\
Sodium & 1.428571 & Strontium & 1.589286 & Ununtrium & 1.75 \\
Magnesium & 1.303571 & Indium & 1.464286 & Flerovium & 1.625 \\
\hline
\end{tabular}


Aluminium

1.178571

Tin

1.339286

Ununpentium

1.5

Silicon

1.053571

Antimony

1.214286

Livermorium

1.375

Phosphorus

0.928571

Tellurium

1.089286

Ununseptium

1.25

Sulfur

0.803571

Iodine

0.964286

Ununoctium

1.125

Chlorine

0.678571

Xenon

0.839286

After we apply the equation, we compare each number of element with other by using Excel and arrange them descending; that means from the biggest atomic size to the smallest one, to have the final order shown in Table 2.

Table 2. Arranging the Atomic size of the elements (which has the biggest number is the largest size)

\begin{tabular}{llllll}
\hline Element & S & Element & S & Element & S \\
\hline Francium & 2 & Tin & 1.339286 & Radon & 0.982143 \\
Radium & 1.875 & Gallium & 1.321429 & Iodine & 0.964286 \\
Cesium & 1.857143 & Magnesium & 1.303571 & Selenium & 0.946429 \\
Ununtrium & 1.75 & Lithium & 1.285714 & Phosphorus & 0.928571 \\
Barium & 1.732143 & Ununseptium & 1.25 & Carbon & 0.910714 \\
Rubidium & 1.714286 & Polonium & 1.232143 & Xenon & 0.839286 \\
Flerovium & 1.625 & Antimony & 1.214286 & Bromine & 0.821429 \\
Thallium & 1.607143 & Germanium & 1.196429 & Sulfur & 0.803571 \\
Strontium & 1.589286 & Aluminium & 1.178571 & Nitrogen & 0.785714 \\
Potassium & 1.571429 & Beryllium & 1.160714 & Krypton & 0.696429 \\
Ununpentium & 1.5 & Hydrogen & 1.142857 & Chlorine & 0.678571 \\
Lead & 1.482143 & Ununoctium & 1.125 & Oxygen & 0.660714 \\
Indium & 1.464286 & Astatine & 1.107143 & Argon & 0.553571 \\
Calcium & 1.446429 & Tellurium & 1.089286 & Fluorine & 0.535714 \\
Sodium & 1.428571 & Arsenic & 1.071429 & Neon & 0.410714 \\
Livermorium & 1.375 & Silicon & 1.053571 & Helium & 0.267857 \\
Bismuth & 1.357143 & Boron & 1.035714 & & \\
\hline & & & & & \\
\hline
\end{tabular}

From the Table 2, the biggest atomic size is Francium with special number equal 2, on the other hand the lowest atomic size is Helium with $\mathrm{S}=0.267857$. So we can realize the position of these two elements directly, and have a priority idea about others elements 
position in the periodic table. From the table we can compare between the elements, for example take the Lead with $\mathrm{S}=1.482143$, this number give the Lead a special atomic size, if we take any value less than this that means the elements with that value has smaller atomic size and the opposite if we take larger than a number of lead. Now, the effective nuclear charge can be known also in the same way of the atomic size, apply the equation and arrange the result of the number of elements to have the data appears in the next table.

Table 3. Arranging the elements with respect to their Effective nuclear charge (which has the biggest number is the largest Effective nuclear charge), by applying equation 1

\begin{tabular}{llllll}
\hline Element & $\mathbf{S}$ & Element & $\mathbf{S}$ & Element & $\mathbf{S}$ \\
\hline Francium & 2 & Tin & 1.339286 & Radon & 0.982143 \\
Radium & 1.875 & Gallium & 1.321429 & Iodine & 0.964286 \\
Cesium & 1.857143 & Magnesium & 1.303571 & Selenium & 0.946429 \\
Ununtrium & 1.75 & Lithium & 1.285714 & Phosphorus & 0.928571 \\
Barium & 1.732143 & Ununseptium & 1.25 & Carbon & 0.910714 \\
Rubidium & 1.714286 & Polonium & 1.232143 & Xenon & 0.839286 \\
Flerovium & 1.625 & Antimony & 1.214286 & Bromine & 0.821429 \\
Thallium & 1.607143 & Germanium & 1.196429 & Sulfur & 0.803571 \\
Strontium & 1.589286 & Aluminium & 1.178571 & Nitrogen & 0.785714 \\
Potassium & 1.571429 & Beryllium & 1.160714 & Krypton & 0.696429 \\
Ununpentium & 1.5 & Hydrogen & 1.142857 & Chlorine & 0.678571 \\
Lead & 1.482143 & Ununoctium & 1.125 & Oxygen & 0.660714 \\
Indium & 1.464286 & Astatine & 1.107143 & Argon & 0.553571 \\
Calcium & 1.446429 & Tellurium & 1.089286 & Fluorine & 0.535714 \\
Sodium & 1.428571 & Arsenic & 1.071429 & Neon & 0.410714 \\
Livermorium & 1.375 & Silicon & 1.053571 & Helium & 0.267857 \\
Bismuth & 1.357143 & Boron & 1.035714 & & \\
\hline & & & & & \\
\hline
\end{tabular}

From the Table 3, the element which has the biggest Effective nuclear charge is Francium, also the lowest is Helium, and the comparing between elements can be done easy. Also arrangement of elements due to the ionization energy obtain using Eq.1, and the result is in the Table 4. 
Table 4. Arranging the ionization energy of the elements (which has the biggest number is the lowest ionization energy) using equation 1

\begin{tabular}{llllll}
\hline Element & S & Element & S & Element & S \\
\hline Helium & 0.267857 & Silicon & 1.053571 & Livermorium & 1.375 \\
Neon & 0.410714 & Arsenic & 1.071429 & Sodium & 1.428571 \\
Fluorine & 0.535714 & Tellurium & 1.089286 & Calcium & 1.446429 \\
Argon & 0.553571 & Astatine & 1.107143 & Indium & 1.464286 \\
Oxygen & 0.660714 & Ununoctium & 1.125 & Lead & 1.482143 \\
Chlorine & 0.678571 & Hydrogen & 1.142857 & Ununpentium & 1.5 \\
Krypton & 0.696429 & Beryllium & 1.160714 & Potassium & 1.571429 \\
Nitrogen & 0.785714 & Aluminium & 1.178571 & Strontium & 1.589286 \\
Sulfur & 0.803571 & Germanium & 1.196429 & Thallium & 1.607143 \\
Bromine & 0.821429 & Antimony & 1.214286 & Flerovium & 1.625 \\
Xenon & 0.839286 & Polonium & 1.232143 & Rubidium & 1.714286 \\
Carbon & 0.910714 & Ununseptium & 1.25 & Barium & 1.732143 \\
Phosphorus & 0.928571 & Lithium & 1.285714 & Ununtrium & 1.75 \\
Selenium & 0.946429 & Magnesium & 1.303571 & Cesium & 1.857143 \\
Iodine & 0.964286 & Gallium & 1.321429 & Radium & 1.875 \\
Radon & 0.982143 & Tin & 1.339286 & Francium & 2 \\
Boron & 1.035714 & Bismuth & 1.357143 & & \\
\hline & & & & & \\
\hline
\end{tabular}

From the Table 4, Helium has the highest ionization energy; conversely the Francium has the least ionization energy value. Using the data from the previous tables, we can express the values as shown in Table 5. If we compare between Table 3 and Table 4, it is clear they are the same and that fit with the natural of the elements on the periodic table, obtained by using equation (1) and have the value of the elements fit with there is position in the periodic Table 5.

Table 5. Applying the Equation 1 to elements within the periodic table

\section{IA}

$\mathrm{H}$

IIA

IIIA

IVA

VA

VIA

VIIA

VIIIA

1.142857

\begin{tabular}{llllllll}
\hline $\mathrm{Li}$ & $\mathrm{Be}$ & $\mathrm{B}$ & $\mathrm{C}$ & $\mathrm{N}$ & $\mathrm{O}$ & $\mathrm{F}$ & $\mathrm{Ne}$ \\
1.285714 & 1.160714 & 1.035714 & 0.910714 & 0.785714 & 0.660714 & 0.535714 & 0.410714 \\
$\mathrm{Na}$ & $\mathrm{Mg}$ & $\mathrm{Al}$ & $\mathrm{Si}$ & $\mathrm{P}$ & $\mathrm{S}$ & $\mathrm{Cl}$ & $\mathrm{Ar}$ \\
\hline
\end{tabular}




\begin{tabular}{llllllll}
\hline 1.428571 & 1.303571 & 1.178571 & 1.053571 & 0.928571 & 0.803571 & 0.678571 & 0.553571 \\
$\mathrm{~K}$ & $\mathrm{Ca}$ & $\mathrm{Ga}$ & $\mathrm{Ge}$ & $\mathrm{As}$ & $\mathrm{Se}$ & $\mathrm{Br}$ & $\mathrm{Kr}$ \\
1.571429 & 1.446429 & 1.321429 & 1.196429 & 1.071429 & 0.946429 & 0.821429 & 0.696429 \\
$\mathrm{Rb}$ & $\mathrm{Sr}$ & $\mathrm{In}$ & $\mathrm{Sn}$ & $\mathrm{Sb}$ & $\mathrm{Te}$ & $\mathrm{I}$ & $\mathrm{Xe}$ \\
1.714286 & 1.589286 & 1.464286 & 1.339286 & 1.214286 & 1.089286 & 0.964286 & 0.839286 \\
$\mathrm{Cs}$ & $\mathrm{Ba}$ & $\mathrm{Ti}$ & $\mathrm{Pb}$ & $\mathrm{Bi}$ & $\mathrm{Po}$ & $\mathrm{At}$ & $\mathrm{Rn}$ \\
1.857143 & 1.732143 & 1.607143 & 1.482143 & 1.357143 & 1.232143 & 1.107143 & 0.982143 \\
$\mathrm{Fr}$ & $\mathrm{Ra}$ & $\mathrm{Uut}$ & $\mathrm{Fi}$ & $\mathrm{Uup}$ & $\mathrm{Lv}$ & $\mathrm{Uus}$ & $\mathrm{Uuo}$ \\
2 & 1.875 & 1.75 & 1.625 & 1.5 & 1.375 & 1.25 & 1.125 \\
\hline
\end{tabular}

\section{Discussion}

The periodic table element trends are detailed arrangements in the periodic table that demonstrate various aspects of a given element, including its size and electronic properties. They also provide a tool for predicting the properties of an element. These trends are found and exist because of the similar atomic structure of the elements within their respective families of groups or periods and because of the periodic nature of the elements. The main trends of the periodic table include: electronegativity, ionization energy, electronic affinity, atomic radius, melting Point and metallic character.

\subsection{Atomic Size Trends}

Atom size can be measured by knowing the atomic radius, which is half the distance between the nuclei of two atoms (similar to a radius half the diameter of a circle), but because it is difficult to measure the size of the elements (radius also) there is a possibility to calculate the atomic radii with the functions of quantum mechanics. The fact that the radial values obtained by such calculations are not identical to any of the experimentally measured sets of values offers a possibility to compare the intrinsic sizes of all elements and to clearly show that the atomic size varies at regular intervals, thus it is easier to compare the size using equation 1.

The atomic size gradually decreases from left to right within the same period of elements. This is because electrons are added to the same shell over a period or family of elements. The effect of increasing the number of protons is greater than that of increasing the number of electrons; hence there is a greater nuclear pull; This means that the nucleus attracts electrons with greater force and brings the shell of the atoms closer to the nucleus. The valence electrons stay closer to the nucleus of the atom. The atomic radius decreases as shown in Table 6. 
Table 6. Periodic table showing Atomic size trend

\begin{tabular}{|c|c|c|c|c|c|c|c|c|}
\hline & & & Atomi & Size in & reasing & & & \\
\hline & IA & & & & & & & VIIIA \\
\hline 0.0 & $\begin{array}{c}\mathrm{H} \\
1.142857\end{array}$ & IIA & IIIA & IVA & VA & VIA & VIIA & $\begin{array}{c}\mathrm{He} \\
0.267857\end{array}$ \\
\hline 寻 & $\begin{array}{c}\mathrm{Li} \\
1.285714\end{array}$ & $\begin{array}{c}\mathrm{Be} \\
1.160714\end{array}$ & $\begin{array}{c}\mathrm{B} \\
1.035714\end{array}$ & $\begin{array}{c}\mathrm{C} \\
0.910714\end{array}$ & $\begin{array}{c}\mathrm{N} \\
0.785714\end{array}$ & $\begin{array}{c}0 \\
0.660714\end{array}$ & $\begin{array}{c}F \\
0.535714\end{array}$ & $\begin{array}{c}\mathrm{Ne} \\
0.410714\end{array}$ \\
\hline 这 & $\begin{array}{c}\mathrm{Na} \\
1.428571\end{array}$ & $\begin{array}{c}\mathrm{Mg} \\
1.303571\end{array}$ & $\begin{array}{c}\mathrm{Al} \\
1.178571\end{array}$ & $\begin{array}{c}\mathrm{Si} \\
1.053571\end{array}$ & $\begin{array}{c}P \\
0.928571\end{array}$ & $\begin{array}{c}\mathrm{S} \\
0.803571\end{array}$ & $\begin{array}{c}\mathrm{Cl} \\
0.678571\end{array}$ & $\begin{array}{c}\text { Ar } \\
0.553571\end{array}$ \\
\hline $\begin{array}{l}= \\
\Xi\end{array}$ & $\begin{array}{c}\mathrm{K} \\
1.571429\end{array}$ & $\begin{array}{c}\mathrm{Ca} \\
1.446429\end{array}$ & $\begin{array}{c}\mathrm{Ga} \\
1.321429\end{array}$ & $\begin{array}{c}\mathrm{Ge} \\
1.196429\end{array}$ & $\begin{array}{c}\text { As } \\
1.071429\end{array}$ & $\begin{array}{c}\mathrm{Se} \\
0.946429\end{array}$ & $\begin{array}{c}\mathrm{Br} \\
0.821429\end{array}$ & $\begin{array}{c}\mathrm{Kr} \\
0.696429\end{array}$ \\
\hline 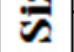 & $\mathrm{Rb}$ & $\mathrm{Sr}$ & In & $\mathrm{Sn}$ & $\mathrm{Sb}$ & $\mathrm{Te}$ & I & $\mathrm{Xe}$ \\
\hline 0 & 1.714286 & 1.589286 & 1.464286 & 1.339286 & 1.214286 & 1.089286 & 0.964286 & 0.839286 \\
\hline 五 & $\begin{array}{cl}\mathrm{Cs} \\
\end{array}$ & $\mathrm{Ba}$ & $\mathrm{Ti}$ & $\mathrm{Pb}$ & $\mathrm{Bi}$ & Po & At & $\mathrm{Rn}$ \\
\hline $\bar{\Xi}$ & 1.857143 & 1.732143 & 1.607143 & 1.482143 & 1.357143 & 1.232143 & 1.107143 & 0.982143 \\
\hline 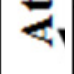 & $\begin{array}{c}\mathrm{Fr} \\
2\end{array}$ & $\begin{array}{c}\mathrm{Ra} \\
1.875\end{array}$ & $\begin{array}{l}\text { Uut } \\
1.75\end{array}$ & $\begin{array}{c}\mathrm{Fi} \\
1.625\end{array}$ & $\begin{array}{l}\text { Uup } \\
1.5\end{array}$ & $\begin{array}{c}\text { Lv } \\
1.375\end{array}$ & $\begin{array}{l}\text { Uus } \\
1.25\end{array}$ & $\begin{array}{c}\text { Uuo } \\
1.125\end{array}$ \\
\hline
\end{tabular}

In the periodic table, atomic size increase from right to left across a row and increase from top to bottom down a column. Because of these two trends, the largest atoms are found in the lower left corner of the periodic table, and the smallest are found in the upper right corner. Plotting the special number (S) obtain from equation (1) with the atomic number for the main group elements from $1 \mathrm{~A}$ to $8 \mathrm{~A}$, the plotting will be as show in Figure 1 (note that figure 1 is pure calculations based on equation 1). Also Figure 2 shows the actual and real periodic variation of atomic size with atomic number. comparing these two plots there is a similarity to the plot of atomic size versus atomic number.

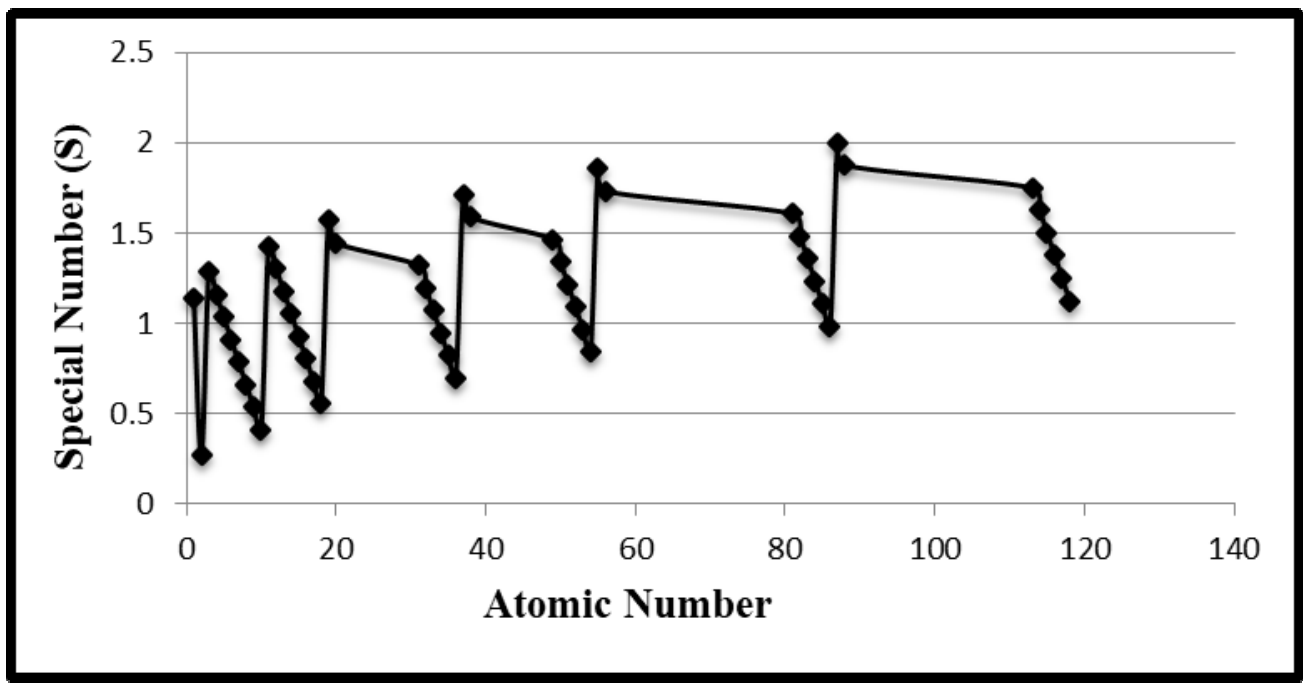

Figure 1. A plot of atomic number with the special number of elements (S). 


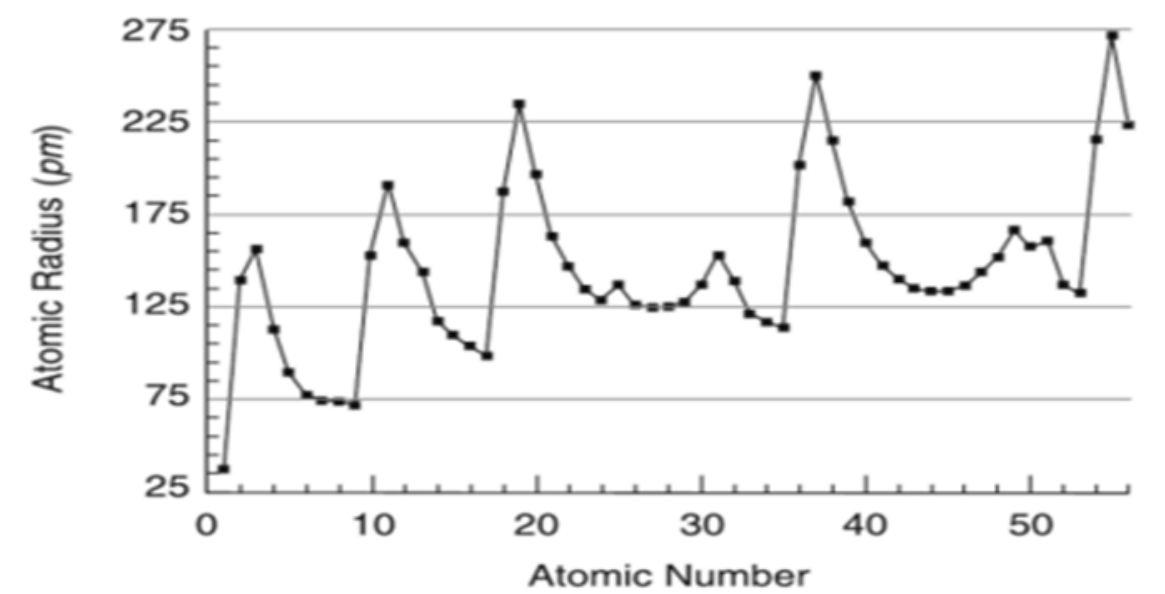

Figure 2. Atomic radius against atomic number

As shown in Figure 1, it is clear that at the first 20 elements the relation is leaner that confirm the result of equation (1). There is a striking resemblances and similarities between figure 1 data (obtained from equation 1) and figure 2 data (represents the real and actual values)

\subsection{Ionization Energy Trends}

Another factor that affects ionization energy is electron shielding. Electron shielding describes the ability of an atom's inner electrons to shield its positively-charged nucleus from its valence electrons. Ionization energy is the energy required to remove an electron from a neutral atom in its gaseous phase.

Generally, elements on the right side of the periodic table have a higher ionization energy because their valence shell is nearly filled, on the other hand, elements on the left side of the periodic table have low ionization energy because of their predisposition to lose electrons and become cations. So, ionization energy increases from left to right on the periodic. From table 6 and 7, Ionization energies decrease as atomic size increase.

Table 7. Periodic table showing ionization energy trend

\begin{tabular}{|c|c|c|c|c|c|c|c|c|}
\hline \multicolumn{8}{|c|}{ Increasing Ionization Energy } & \multirow{13}{*}{ 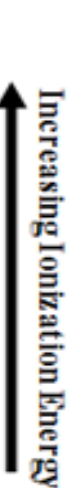 } \\
\hline & & & & & & & & \\
\hline$\underset{1.142857}{H}$ & IIA & IIIA & IVA & VA & VIA & VIIA & $\begin{array}{c}\mathrm{He} \\
0.267857\end{array}$ & \\
\hline $\begin{array}{c}\mathrm{Li} \\
1.285714\end{array}$ & $\begin{array}{c}\mathrm{Be} \\
1.160714\end{array}$ & $\begin{array}{c}\mathrm{B} \\
1.035714\end{array}$ & $\begin{array}{ll}\mathrm{C} \\
0.910714\end{array}$ & $\begin{array}{ll}N \\
0.785714\end{array}$ & $\begin{array}{c}0 \\
0.660714\end{array}$ & $\frac{F}{F}$ & $\begin{array}{c}\mathrm{Ne} \\
0.410714\end{array}$ & \\
\hline $\mathrm{N}_{2}$ & $\mathrm{Mg}$ & $\mathrm{Al}$ & $S_{1}$ & ${ }_{P}^{P}$ & s & $\mathrm{C}$ & Af & \\
\hline$\frac{1.428571}{K}$ & $\frac{1.303571}{C_{3}}$ & $\frac{1.178571}{G_{2}}$ & $\frac{1.053571}{G e}$ & $\frac{0.928571}{\mathrm{As}^{5}}$ & $\frac{0.803571}{\mathrm{Se}}$ & $\frac{0.678571}{\mathrm{Br}}$ & $\frac{0.553571}{K_{f}}$ & \\
\hline $\begin{array}{c}\hat{A} \\
1.571429\end{array}$ & 1.446429 & 1.321429 & 1.196429 & $\begin{array}{c}\text { As } \\
1.071429\end{array}$ & $\begin{array}{c}\mathrm{Se} \\
0.946429\end{array}$ & $\begin{array}{c}\mathrm{Br} \\
0.821429\end{array}$ & $\begin{array}{c}\mathrm{Kr} \\
0.696429\end{array}$ & \\
\hline$R b$ & Sr & In & $\mathrm{Su}$ & Sb & $\mathrm{Te}$ & & $\mathrm{Xe}$ & \\
\hline 1.714286 & 1.589286 & 1.464286 & 1.339286 & 1.214286 & 1.089286 & 0.964286 & 0.839286 & \\
\hline$C_{5}$ & $\mathrm{Ba}$ & $\mathrm{Ti}$ & $\mathrm{Pb}$ & $\mathrm{Bi}$ & $P_{0}$ & At & $R n$ & \\
\hline 1.857143 & 1.732143 & 1.607143 & 1.482143 & 1.357143 & 1.232143 & 1.107143 & 0.982143 & \\
\hline$F_{t}$ & $\mathrm{Ra}$ & Uut & $\mathrm{Fi}_{i}$ & Uup & $\mathrm{Lv}$ & Uus & Uuo & \\
\hline 2 & 1.875 & 1.75 & 1.625 & 1.5 & 1.375 & 1.25 & 1.125 & \\
\hline
\end{tabular}




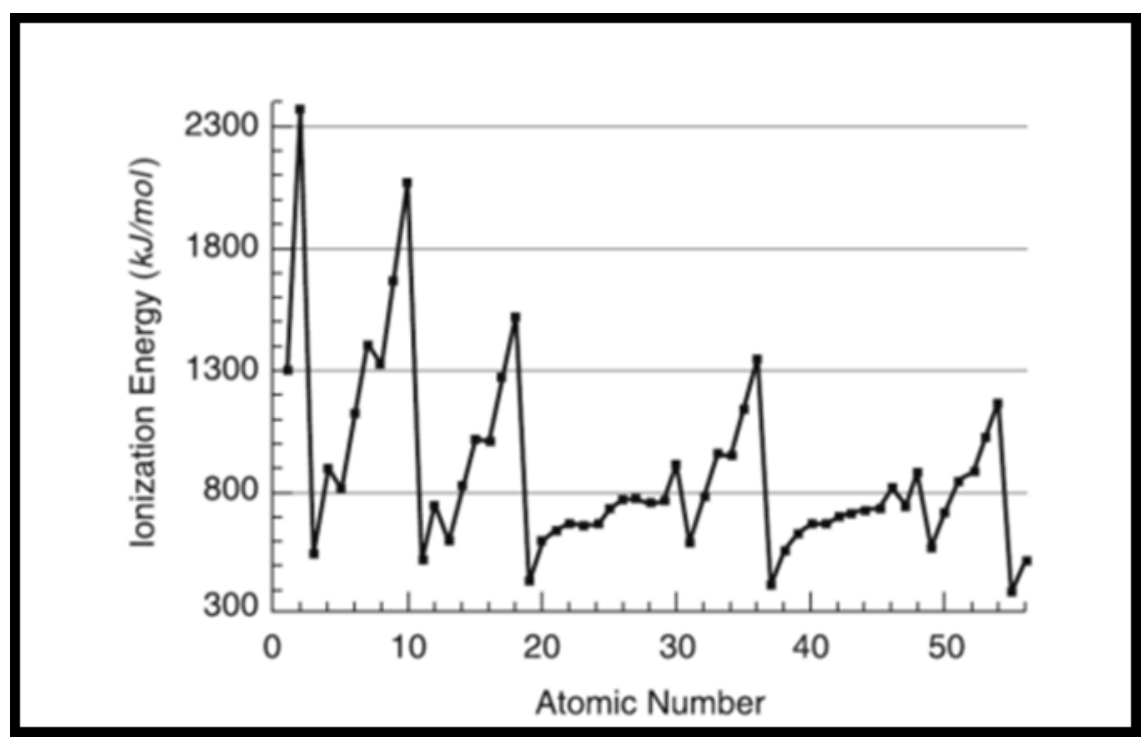

Figure 3. Ionization energy plotted against atomic number ${ }^{10}$

Table 4 show that successive ionization energies for an element increase steadily; removing the first electron reduces the repulsive forces among the remaining electrons, so the attraction of the remaining electrons to the nucleus is stronger.

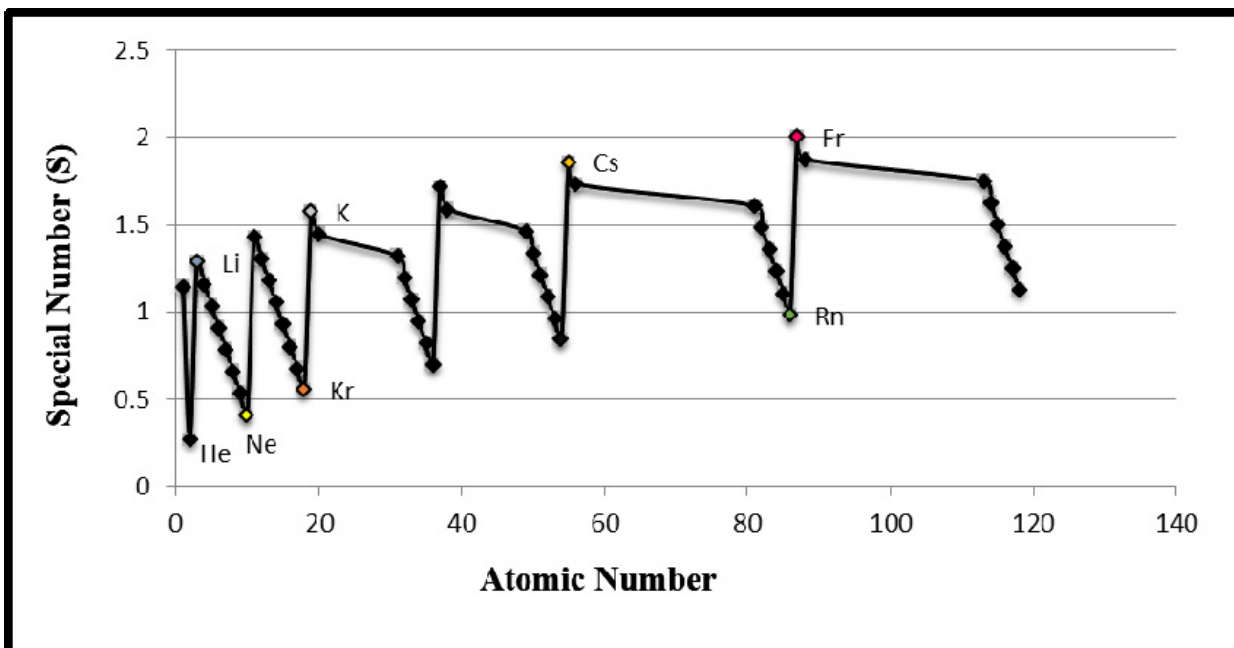

Figure 4. Special number (S) from table 4 plotted against atomic number

Plots 3 and 4 illustrate three important trends:

1. The changes seen in the second ( $\mathrm{Li}$ to $\mathrm{Ne}$ ), third ( $\mathrm{Na}$ to $\mathrm{Ar}$ ), fifth ( $\mathrm{Rb}$ to $\mathrm{Xe}$ ), and sixth (Cs to $\mathrm{Rn}$ ) rows of the $\mathrm{s}$ and $\mathrm{p}$ blocks follow a pattern similar to the pattern described for the third row of the periodic table.

2. First ionization energies generally decrease down a column with increasing principal quantum number (n).

3. Filled inner shells are effective at screening the valence electrons, so there is a relatively small increase in the effective nuclear charge. Consequently, the atoms become larger as they 
acquire electrons. Valence electrons that are farther from the nucleus are less tightly bound, making them easier to remove, which causes ionization energies to decrease. A larger radius corresponds to a lower ionization energy.

4. Because of the first two trends, the elements that form positive ions most easily (have the lowest ionization energies) lie in the lower left corner of the periodic table, whereas those that are hardest to ionize lie in the upper right corner of the periodic table. Consequently, ionization energies generally increase diagonally from lower left (Fr) to upper right ( $\mathrm{He})$.

\subsection{Effective Nuclear Charge Trend}

Trends in atomic size result from differences in the effective nuclear charges, for all elements except $\mathrm{H}$, the effective nuclear charge is always less than the actual nuclear charge because of shielding effects. The greater the effective nuclear charge, the more strongly the outermost electrons are attracted to the nucleus and the smaller the atomic radius. The atoms in the second row of the periodic table ( $\mathrm{Li}$ through $\mathrm{Ne}$ ) illustrate the effect of electron shielding.

Table 8. Periodic table showing effective nuclear charge trend

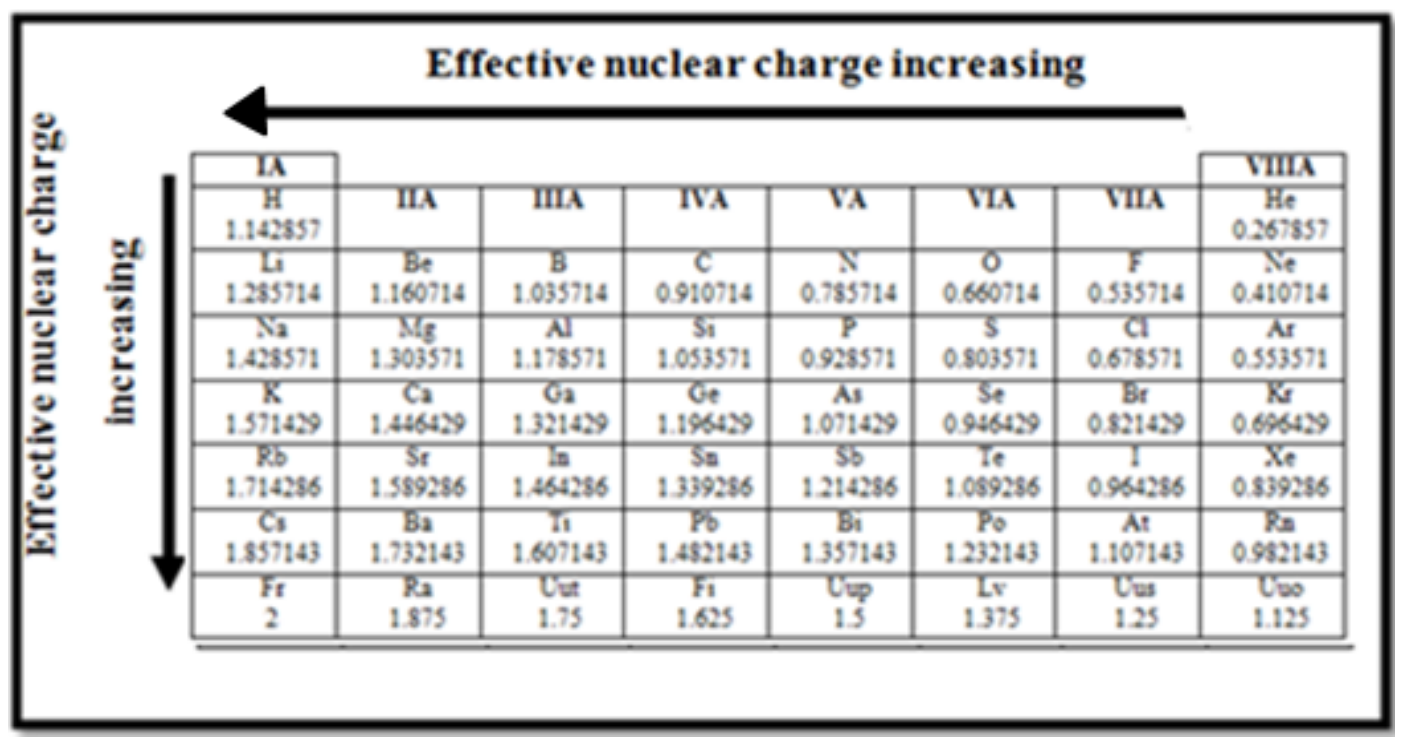

From Table 8, the atoms in the second row of the periodic table ( $\mathrm{Li}$ through $\mathrm{Ne}$ ) illustrate the effect of electron shielding, all have a filled $1 \mathrm{~s}^{2}$ inner shell, but as we go from left to right across the row, the nuclear charge increases. Although electrons are being added to the $2 \mathrm{~s}$ and $2 p$ orbitals, electrons in the same principal shell are not very effective at shielding one another from the nuclear charge. Thus the single $2 \mathrm{~s}$ electron in lithium experiences an effective nuclear charge of approximately +1 because the electrons in the filled $1 \mathrm{~s} 2$ shell effectively neutralize two of the three positive charges in the nucleus. In contrast, the two $2 \mathrm{~s}$ electrons in beryllium do not shield each other very well, although the filled $1 \mathrm{~s}^{2}$ shell effectively neutralizes two of the four positive charges in the nucleus. This means that the effective nuclear charge experienced by the 2 s electrons in beryllium is between +1 and +2 . Consequently, beryllium is significantly smaller than lithium. Similarly, as we proceed across the row, the increasing nuclear charge is not effectively neutralized by the electrons being 
added to the $2 \mathrm{~s}$ and $2 \mathrm{p}$ orbitals. The result is a steady increase in the effective nuclear charge and a steady decrease in atomic size.

In group 1, the size of the atoms increases substantially going down the column. It may at first seem reasonable to attribute this effect to the successive addition of electrons to ns orbitals with increasing values of $n$. However, it is important to remember that the radius of an orbital depends dramatically on the nuclear charge. As we go down the column of the group 1 elements, the principal quantum number $n$ increases from 2 to 7 , and the nuclear charge increases.

Also the atomic size trends in a similar way as the affective nuclear charge, depending on plot 1 , the effective nuclear charge can be explained in terms of the atomic size.

\section{Conclusions}

Theoretical development of an equation for the periodic table from which several parameters can be extracted that fit with the actual periodic table trend. Also the linear relation appears in plotting with atomic number for each group and period in general. Theoretical development of an equation for the periodic table from which several parameters can be extracted that fit with the actual periodic

\section{References}

Daniel, R., Scott, G., \& David, B. (2009). Cengage Learning.

Hans-Jürgen, Quadbeck-Seeger (2007). The Periodic Table Through History, Wiley

Lambert, M., Surhone, M. T., \& Timpledon, S. (2010). Periodic Table: Periodic Table, Chemical Element, History of the Periodic Table, Dmitri Mendeleev, Atomic Number, Electron Configuration, Chemical Symbol, Atomic Mass, Electronegativity, Betascript Publishing.

N. V. Sidgwick. (1957). Atomic Structure and the Periodic Table, Murray.

Primo, L., \& Raymond, P. (2012). The Periodic Table, Penguin.

Raymond, R. The Periodic Table, New York.

Rod, B., \& Alan, J. (2003). Structure, Bonding and Main Group Chemistry, Nelson Thornes, 2003.

Roger, S., \& Maureen, S. (2012). Cambridge Checkpoints VCE Chemistry Units 3 and 4, Cambridge University Press.

Suzanne, S. (2007). Elements and the Periodic Table, Rosen Classroom.

\section{Copyright Disclaimer}

Copyright reserved by the authors.

This article is an open-access article distributed under the terms and conditions of the Creative Commons Attribution license (http://creativecommons.org/licenses/by/4.0/). 